\begin{tabular}{|c|c|}
\hline Title & Three dimensional imaging of biological cells with picosecond ultrasonics \\
\hline Author(s) & $\begin{array}{l}\text { Danworaphong, Sorasak; Tomoda, Motonobu; Matsumoto, Y uki; Matsuda, Osamu; O hashi, Toshiro; W atanabe, } \\
\text { Hiromu; Nagay ama, Masafumi; Gohara, Kazutoshi; Otsuka, Paul H.; Wright, Oliver B. }\end{array}$ \\
\hline Citation & $\begin{array}{l}\text { A pplied phy sics letters, 106(16), } 163701 \\
\text { https://doi.org/10.1063/1.4918275 }\end{array}$ \\
\hline Issue Date & 2015-04-21 \\
\hline Doc URL & http:/hdl. handle.net/2115/59330 \\
\hline Rights & $\begin{array}{l}\text { Copyright } 2015 \text { A merican Institute of Phy sics. This article may be downloaded for personal use only. A ny other use } \\
\text { requires prior permission of the author and the A merican Institute of Physics. The following article appeared in A ppl. } \\
\text { Phys. Lett. 106, 163701, 2015, and may be found at http://dx.doi.org/10.1063/1.4918275 }\end{array}$ \\
\hline Type & article \\
\hline File Information & 1.4918275.pdf \\
\hline
\end{tabular}

Instructions for use 


\section{AIP / Applied Physics \\ Letters}

\section{Three-dimensional imaging of biological cells with picosecond ultrasonics}

Sorasak Danworaphong, Motonobu Tomoda, Yuki Matsumoto, Osamu Matsuda, Toshiro Ohashi, Hiromu

Watanabe, Masafumi Nagayama, Kazutoshi Gohara, Paul H. Otsuka, and Oliver B. Wright

Citation: Applied Physics Letters 106, 163701 (2015); doi: 10.1063/1.4918275

View online: http://dx.doi.org/10.1063/1.4918275

View Table of Contents: http://scitation.aip.org/content/aip/journal/apl/106/16?ver=pdfcov

Published by the AIP Publishing

\section{Articles you may be interested in}

Label-free three-dimensional imaging of cell nucleus using third-harmonic generation microscopy

Appl. Phys. Lett. 105, 103705 (2014); 10.1063/1.4895577

Magnetic approaches to study collective three-dimensional cell mechanics in long-term cultures (invited) J. Appl. Phys. 115, 172616 (2014); 10.1063/1.4870918

Non-invasive optoacoustic probing of the density and stiffness of single biological cells

J. Appl. Phys. 112, 124702 (2012); 10.1063/1.4769294

Fabrication of three-dimensional structures for the assessment of cell mechanical interactions within cell monolayers

J. Vac. Sci. Technol. B 28, C6K1 (2010); 10.1116/1.3511435

Three-dimensional finite element modeling of guided ultrasound wave propagation in intact and healing long bones

J. Acoust. Soc. Am. 121, 3907 (2007); 10.1121/1.2354067

Frustrated by

old technology?

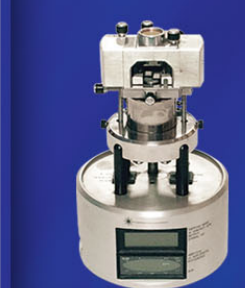

Is your AFM dead

and can't be repaired?

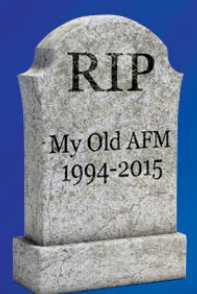

Sick of bad customer support?

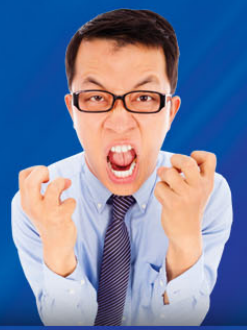

It is time to upgrade your AFM Minimum $\$ 20,000$ trade-in discount for purchases before August 31st

Asylum Research is today's technology leader in AFM 


\title{
Three-dimensional imaging of biological cells with picosecond ultrasonics
}

\author{
Sorasak Danworaphong, ${ }^{1}$ Motonobu Tomoda, ${ }^{2}$ Yuki Matsumoto, ${ }^{2}$ Osamu Matsuda, ${ }^{2}$ \\ Toshiro Ohashi, ${ }^{3}$ Hiromu Watanabe, ${ }^{2}$ Masafumi Nagayama, ${ }^{2}$ Kazutoshi Gohara, ${ }^{2}$ \\ Paul H. Otsuka, ${ }^{2}$ and Oliver B. Wright ${ }^{2, a)}$ \\ ${ }^{1}$ School of Science, Walailak University, Thasala, Nakhon Si Thammarat 80160, Thailand \\ ${ }^{2}$ Division of Applied Physics, Graduate School of Engineering, Hokkaido University, \\ Sapporo 060-8628, Japan \\ ${ }^{3}$ Division of Human Mechanical Systems and Design, Graduate School of Engineering, Hokkaido University, \\ Sapporo 060-8628, Japan
}

(Received 5 February 2015; accepted 20 March 2015; published online 20 April 2015)

\begin{abstract}
We use picosecond ultrasonics to image animal cells in vitro-a bovine aortic endothelial cell and a mouse adipose cell—fixed to Ti-coated sapphire. Tightly focused ultrashort laser pulses generate and detect $\mathrm{GHz}$ acoustic pulses, allowing three-dimensional imaging $(x, y$, and $t)$ of the ultrasonic propagation in the cells with $\sim 1 \mu \mathrm{m}$ lateral and $\sim 150 \mathrm{~nm}$ depth resolutions. Time-frequency representations of the continuous-wavelet-transform amplitude of the optical reflectivity variations inside and outside the cells show GHz Brillouin oscillations, allowing the average sound velocities of the cells and their ultrasonic attenuation to be obtained as well as the average bulk moduli. (C) 2015 AIP Publishing LLC. [http://dx.doi.org/10.1063/1.4918275]
\end{abstract}

Characterization of the physical properties of cells is essential for understanding their behavior such as mitosis, apoptosis, adhesion, and mobility. ${ }^{1-3}$ In particular, various techniques have been used to investigate the mechanical properties of single cells ${ }^{4}$ for example, embedded particle tracking, ${ }^{5}$ magnetic twist cytometry, ${ }^{6}$ micro-patterned substrates, ${ }^{7}$ micropipette aspiration, ${ }^{8}$ optical traps or laser tweezers, ${ }^{9}$ optical stretchers, ${ }^{10}$ magnetic traps, ${ }^{11}$ microneedles, ${ }^{12}$ atomic force spectroscopy, ${ }^{13}$ and biomembrane force probes. ${ }^{14}$ These techniques mainly provide information concerning cell adhesion and deformation directly related to the cell membrane and cytoskeleton. In contrast, conventional acoustic microscopy allows the non-invasive study of the mechanical properties of the intracellular medium, i.e., the cytoplasm and nucleus. ${ }^{15}$ This technique is sensitive to the sound velocity, density, acoustic impedance, and bulk modulus of cells. Although images and sections of cells have been obtained with this method, full three-dimensional (3D) scanning of a single cell has not been reported. ${ }^{16,17}$

Recently, picosecond ultrasonics has been introduced to characterize single cells after decades of being used to investigate the mechanical and thermal properties of metals and semiconductors on sub-micron scales. ${ }^{18,19}$ This technique monitors $\mathrm{GHz}$ Brillouin oscillations in the time domain, allowing acoustic properties-sound velocity and ultrasonic attenuation-for the nucleus and vacuole of vegetal cells to be measured. ${ }^{20-22}$ In addition, cell density, compressibility and adhesion, as well as mechanical properties of cell walls have been studied with this technique in both vegetal and mammalian cells. ${ }^{23-27}$ In spite of this work, the technique has never been applied to obtain spatiotemporal data that allow 3D imaging of cell properties.

In this letter, we demonstrate 3D cell imaging with picosecond ultrasonics. We investigate two types of mammalian

\footnotetext{
${ }^{\text {a) }}$ Author to whom correspondence should be addressed. Electronic mail: olly@eng.hokudai.ac.jp
}

biological tissues-a bovine aortic endothelial cell and a mouse adipose, i.e., fat cell. Endothelial cells play an important role in physiology of blood vessels and are useful in the study of biomechanics. ${ }^{28,29}$ Fat cells provide an interesting comparison because of their different geometry and contents.

Fluorescence micrographs superimposed on background differential-interference- or phase-contrast images of a typical collection of each type of cell are shown in Figs. 1(b) and 1(c). A bovine endothelial cell, ${ }^{28,33}$ of thickness $\sim 2 \mu \mathrm{m}$, is prepared by use of a standard formalin fixation technique on a $150 \mathrm{~nm}$ polycrystalline Ti film deposited on a sapphire substrate of thickness $0.5 \mathrm{~mm}$. A mouse fat cell, of thickness $\sim 10 \mu \mathrm{m}$, is differentiated from a commercial 3T3-L1 cell $\operatorname{line}^{34}$ and fixed in a similar manner. Each (unstained) cell is covered by a single-cavity microscope slide filled with saline and buffer solutions for the endothelial and fat cells, respectively, and each slide is then placed on an $x-y$ translation stage, allowing 2D raster scans. The experimental setup is shown in Fig. 1(a). An ultrashort-pulse mode-locked Ti:Sapphire laser with a $75.8 \mathrm{MHz}$ repetition rate and a $0.2 \mathrm{ps}$ pulse duration is used for pumping and probing. A 830-nm pump beam of pulse energy $0.1 \mathrm{~nJ}$ (ensuring linear response) is focused by a $50 \times$ objective lens at normal incidence to a $\sim 3 \mu \mathrm{m}$ diameter (full width at half maximum) spot on the film from the substrate side, heating the Ti film from underneath at a chopping frequency of $1 \mathrm{MHz}$. A signal at the chopping frequency is coupled to a lock-in amplifier for high signal-to-noise ratio measurement. ${ }^{19} \mathrm{~A}$ series of $\mathrm{GHz}$ picosecond ultrasonic pulses traverse the cell sample, and are monitored by a 415-nm (frequency-doubled) probe beam with a pulse energy of $0.03 \mathrm{~nJ}$ from the opposite side. This beam is focused to $\sim 2 \mu \mathrm{m}$ diameter spot by a $50 \times$ objective lens sharing the same central axis with the pump beam and temporally scanned up to $800-1000$ ps (after each ultrasonic pulse arrives at the Ti-solution interface) by use of a mechanical delay line. The optical beams impose an overall steady-state temperature rise at the Ti-solution interface 

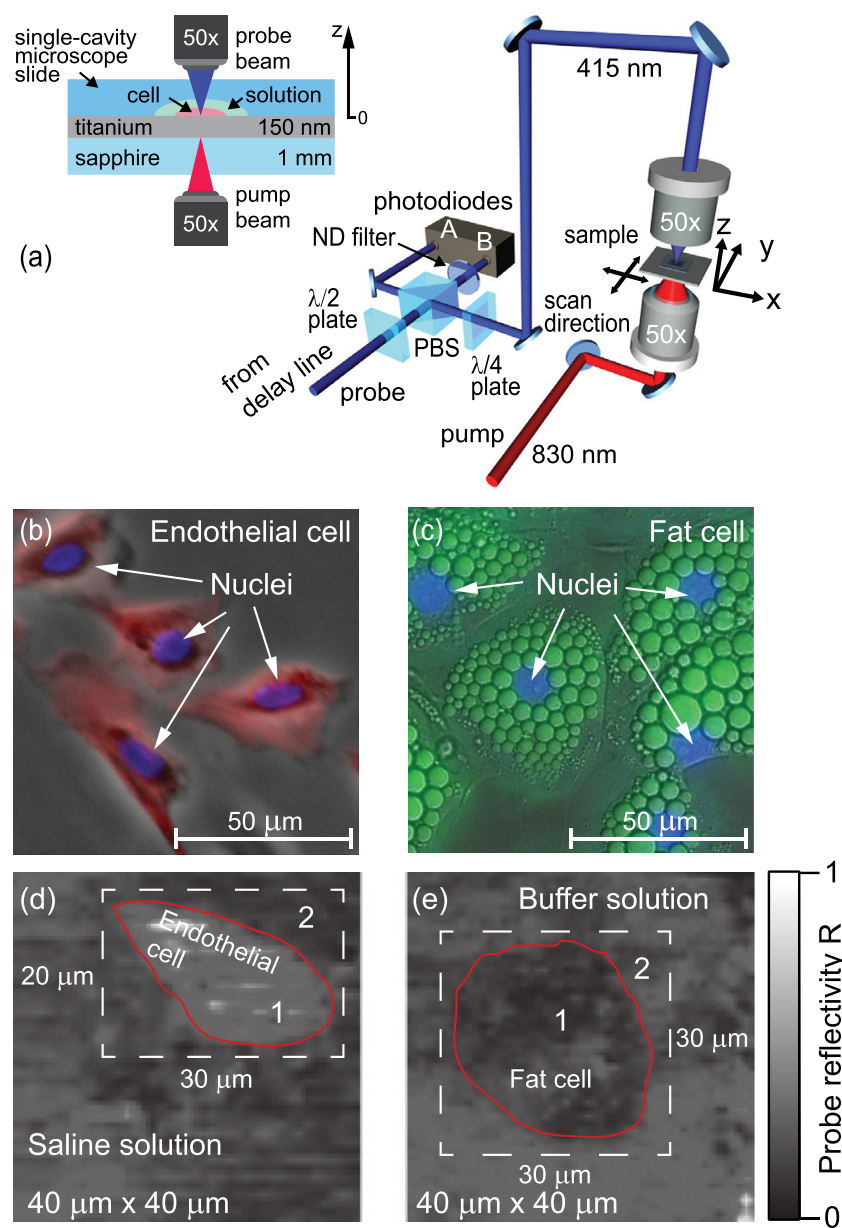

FIG. 1. (a) Experimental setup and sample. PBS: polarization beam splitter. ND filter: neutral density filter. (b) and (c) Fluorescence micrographs of the endothelial and fat cells. In (b), superimposed on a phase-contrast image, actin filaments are stained by rhodamine phalloidin and nuclei by DAPI. In (c), superimposed on a differential-interference-contrast image, neutral lipids are stained by BODIPY 493/503 and nuclei by Hoechst 33342. (d) and (e): images of the normalized probe-beam reflectivity $R$. The white dashed areas are used for analysis. The solid (red) lines are cell boundaries. 1 and 2 indicate the cells and their surrounding solutions.

of $\sim 13 \mathrm{~K}$ above room temperature $\left(25^{\circ} \mathrm{C}\right) .{ }^{30}$ Two photodiodes (A and B in Fig. 1(a)) operating in differential mode are used to measure the probe reflectivity variations $\delta R \sim 10^{-5}$. As the ultrasonic pulses, generated with strain amplitudes $\sim 10^{-4}$ at up to $\sim 100 \mathrm{GHz}$ in the Ti film, ${ }^{35}$ traverse the cells and the solutions, the pulse duration broadens. ${ }^{36}$ However, the optical probe pulses detect only a single frequency as a result of Brillouin scattering, as described later. Spatial and temporal scanning allow 3D imaging $(x, y$, and $t)$ over $40 \mu \mathrm{m} \times 40 \mu \mathrm{m}$ areas with $\sim 1 \mu \mathrm{m}$ and 1 ps resolutions. Acquisition times for each complete 3D data set are typically $7 \mathrm{~h}$ for 800 images with $1 \mu \mathrm{m} / \mathrm{pixel}$, but this did not lead to any evident damage. (Time scans were executed for each $x$ and $y$.) Such movies ${ }^{30}$ allow one to trace the ultrasonic propagation. The acquisition time for a single image $(\sim 30 \mathrm{~s})$ is of the same order as that in super-resolution microscopy techniques such as photoactivated localization microscopy (PALM) and stochastic optical reconstruction microscopy (STORM). ${ }^{31,32}$ For quantitative processing, we identify regions inside and outside the cells from static probe-beam reflectivity $(R)$ images of the cells, as shown in Figs. 1(b) and 1(c). Figures 2(a) and 2(b) show $\delta R(t)$ averaged over the cells and surrounding regions (after subtracting a thermal background signal), whereas (c) and (d) show typical images of $\delta R$ for the two cells. The $\mathrm{GHz}$ oscillations in $\delta R$ arise from interference between probe-beam light reflected from the Ti film and that scattered from the ultrasonic wavefront travelling perpendicular to the film surface in the solution or cell. This so-called Brillouin scattering results in oscillations for normal probe incidence at frequency $f_{B}=2 n v_{l} / \lambda_{p}$, where $n$ and $v_{l}$ are the local refractive index and longitudinal sound velocity $(\sim 1500 \mathrm{~m} / \mathrm{s})$ and $\lambda_{p}$ is the vacuum optical wavelength of the probe. Measuring $f_{B}$ for known (or negligibly varying) $n$ allows one to map $v_{l}$ within the samples. Ultrasonic attenuation can be accessed from the decay in oscillation amplitude.

Rather than work directly with $\delta R(t)$, it is advantageous to follow $f_{B}(t)$ in order to find $v_{l}(t)$. Here, we implement continuous-wavelet transforms (WTs), previously used to analyse $\delta R$ in picosecond ultrasonics to reveal acoustic echoes hidden by Brillouin oscillations, ${ }^{25}$ as well as on sub-picosecond timescales to reveal carrier-phonon interactions ${ }^{37}$ for example. $\delta R(t)$ for the regions inside and outside the cells are averaged and wavelet transformed using the Morlet mother wavelet

$$
M(t)=\left(\frac{1}{\pi}\right)^{1 / 4} \cos (5 t) \exp \left(-\frac{t^{2}}{2}\right)
$$

where in this equation, $t$ is normalized. We plot the wavelettransform amplitude $A_{W T}$ in Figs. 3(a) and 3(b) for the saline solution and endothelial cell and in Figs. 3(c) and 3(d) for the buffer solution and fat cell, respectively. The
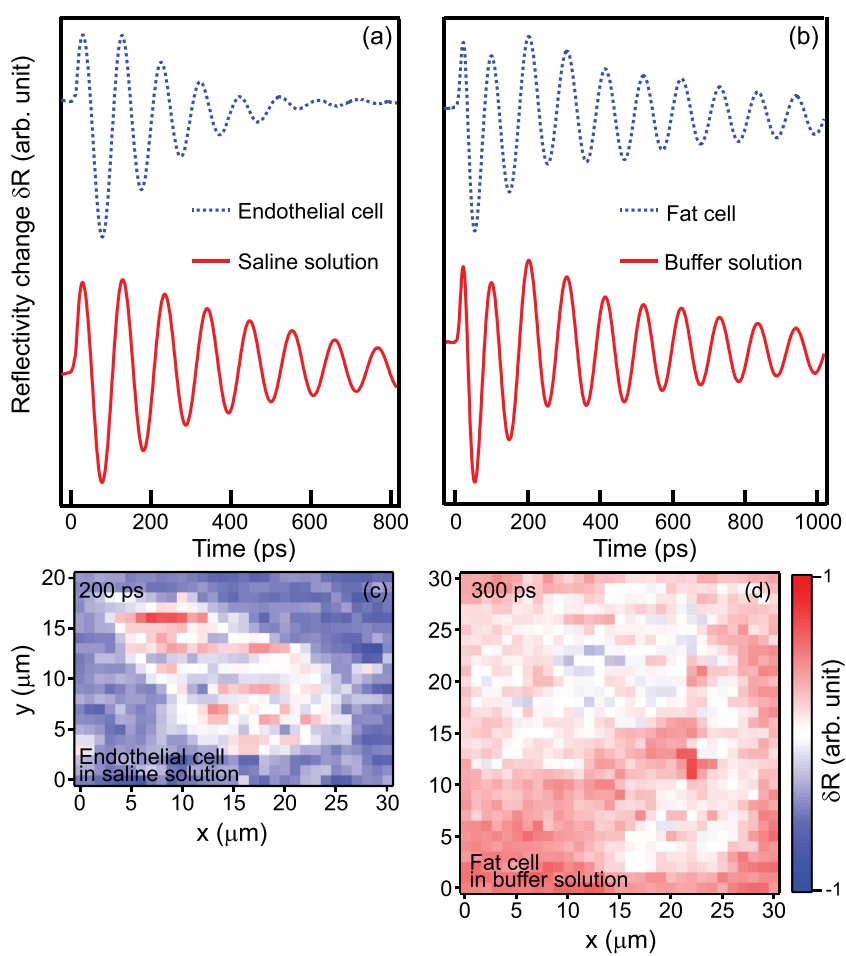

FIG. 2. Average optical reflectivity variations $\delta R$ for (a) endothelial cell and its surrounding solution, and for (b) fat cell and its surrounding solution. (c) and (d) show corresponding images of $\delta R$ at 200 and 300 ps. $^{30}$ 


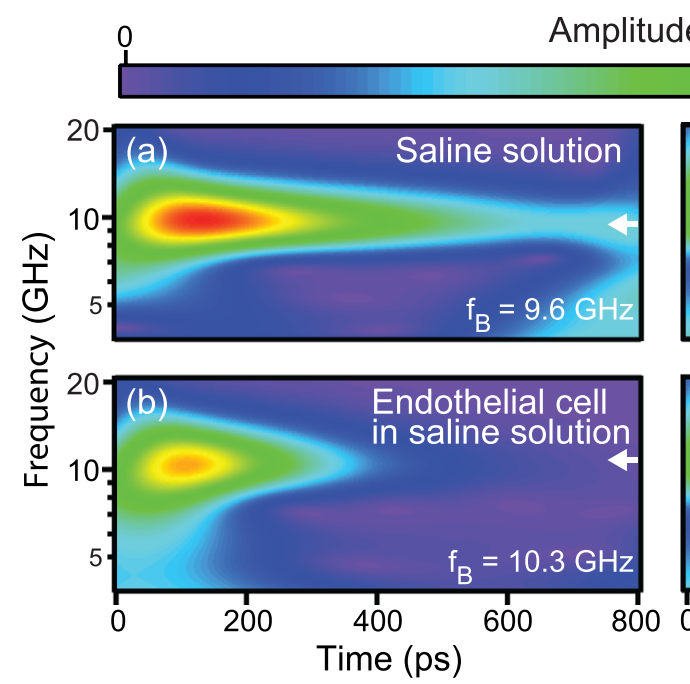

Amplitude $A_{W T}$
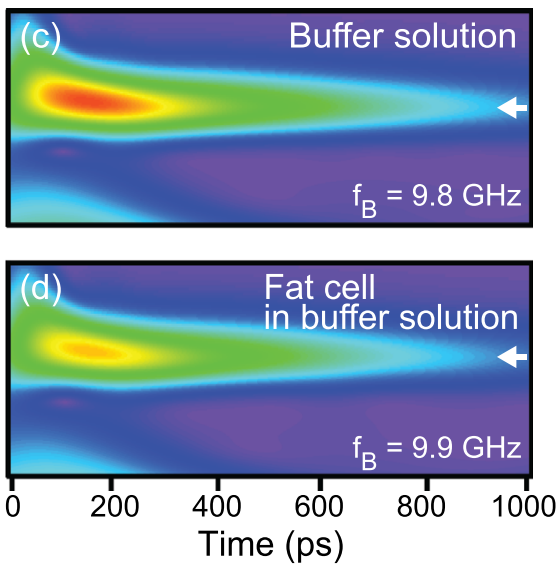

FIG. 3. Time-frequency representation shown by the normalized value of the wavelet-transform amplitude $A_{W T}$. (a) Outside the endothelial cell in the saline solution, and (b) inside this cell. (c) and (d) Equivalent plots for the buffer solution and the fat cell, respectively. The white arrows indicate the Brillouin frequencies $f_{B}$ for each sample. The decays in $A_{W T}$ as time progresses are indicative of the ultrasonic attenuation. corresponding $f_{B}$ are $9.6 \pm 0.1,10.3 \pm 0.1,9.8 \pm 0.1$, and $9.9 \pm 0.1 \mathrm{GHz}$ yielding ultrasonic wavelengths $\sim 0.15 \mu \mathrm{m}$.

Spatially interpolated images of normalized $A_{W T}$ at three separate times are shown in Figs. 4(a)-4(c) for the endothelial cell and in (d)-(f) for the fat cell. Corresponding vertical positions $z$ calculated from the estimated $v_{l}$ are also shown. (The spatial resolution for $z$ is limited to the order of the ultrasonic wavelength $\sim 0.15 \mu \mathrm{m}$.) $A_{W T}(t)$ reveals the ultrasonic attenuation. That of the endothelial cell is clearly greater than that of its surroundings, whereas that of the fat cell is similar. The spatial dependence of $A_{W T}(t)$ shows evidence of inhomogeneity inside the cells, although our signal-to-noise ratio is not sufficient to identify specific internal cell structures. ${ }^{38} A_{W T}(x, y$, and $t)$ is available in movie form. ${ }^{30}$

Given the frequency variation $f_{B}(t)$ and refractive index $n$ one can obtain $v_{l}(t)=f_{B}(t) \lambda_{p} / 2 n$. Here, we assume $n=1.38$ for the endothelial cell and 1.36 for the fat cell. ${ }^{39,40}$ For the surrounding solutions, we use the refractive index of water, $n=1.33,{ }^{41,42}$ as a good approximation. Figures 5(a) and 5(b) show $v_{l}(t)$ derived in this way for the endothelial and fat cells and for their surrounding solutions. For the range of 200-600 ps, ${ }^{43} v_{l}(t)$ for the endothelial cell shows a slight variation that is probably the result of the finite wavelettransform frequency resolution, ${ }^{44}$ whereas for the saline solution $v_{l}(t)$ is, as expected, constant to within the experimental error. The fat cell and its surrounding buffer solution both exhibit a relatively constant $v_{l}(t)$. The average value of $v_{l}$ for the endothelial cell is $1.55 \pm 0.02 \mu \mathrm{m} \mathrm{ns}^{-1}$, while that for the fat cell is $1.51 \pm 0.01 \mu \mathrm{m} \mathrm{ns}^{-1}$. On the other hand, $v_{l}$ for the saline solution is $1.50 \pm 0.02 \mu \mathrm{m} \mathrm{ns}^{-1}$ and that for the buffer solution is $1.53 \pm 0.01 \mu \mathrm{m} \mathrm{ns}^{-1}$. For endothelial cells, $v_{l}$ was reported to be 1.56 (Ref. 45 ), and for fat cells it was reported to be $1.48 \mu \mathrm{m} \mathrm{ns}^{-1},{ }^{46}$ in agreement with our results to within $1 \%$ and $2 \%$.

One can also calculate the corresponding average bulk moduli $B=\rho v_{l}^{2}$, where $\rho$ is the density. Assuming constant average values $\rho=1080 \mathrm{~kg} / \mathrm{m}^{3}$ for the endothelial cell ${ }^{45}$ and $\rho=920 \mathrm{~kg} / \mathrm{m}^{3}$ for the fat cell, ${ }^{47}$ the corresponding moduli are $2.60 \pm 0.05$ and $2.09 \pm 0.02 \mathrm{GPa}$, while that for the saline solution is $2.23 \pm 0.04 \mathrm{GPa}$ and for the buffer solution $2.32 \pm 0.02 \mathrm{GPa}$, obtained using the value $\rho=992.9 \mathrm{~kg} / \mathrm{m}^{3}$

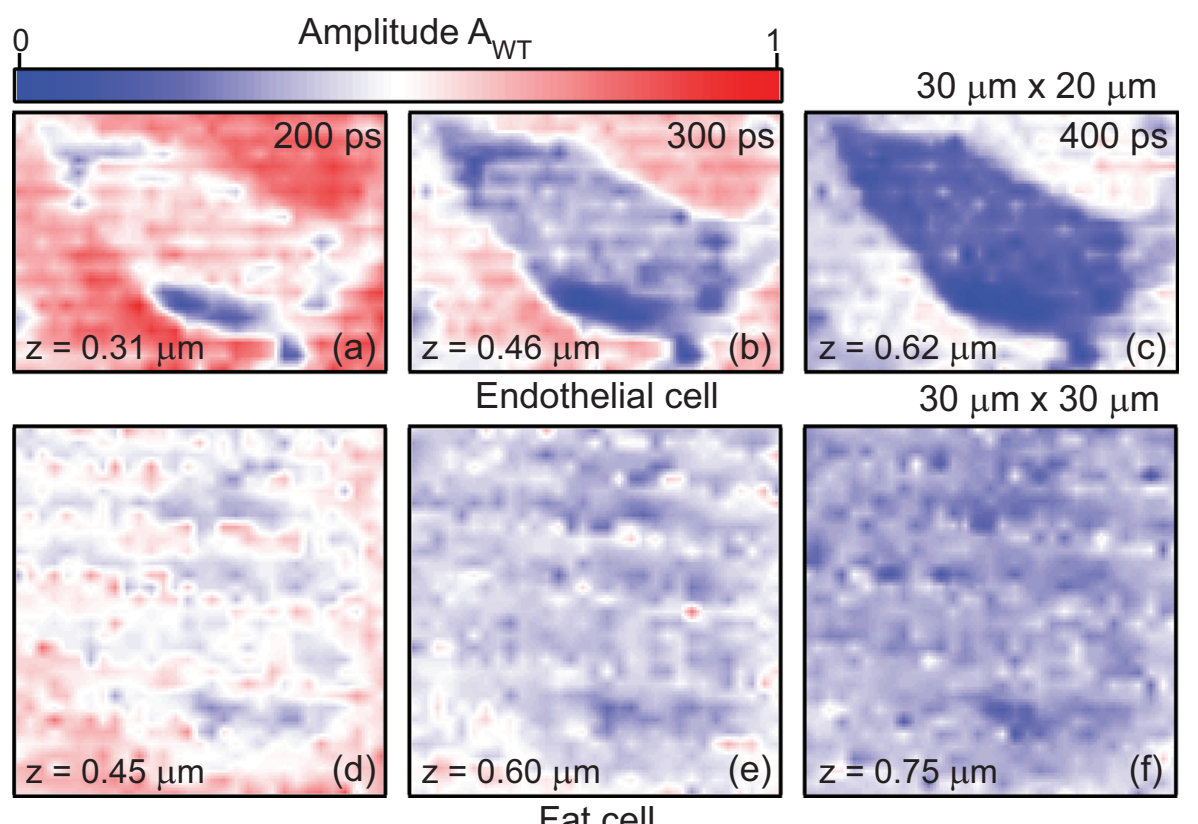

FIG. 4. Normalized WT amplitude images $A_{W T}(x, y)$ at the Brillouin frequency at different times. (a)-(c) At frequency $10.3 \mathrm{GHz}$ for the endothelial cell at 200,300, and 400 ps. (d)-(f) At $9.9 \mathrm{GHz}$ for the fat cell at 300,400 , and $500 \mathrm{ps}$. We also show the calculated average propagation distances, $z$, of the ultrasonic pulse within the cells at these times. 

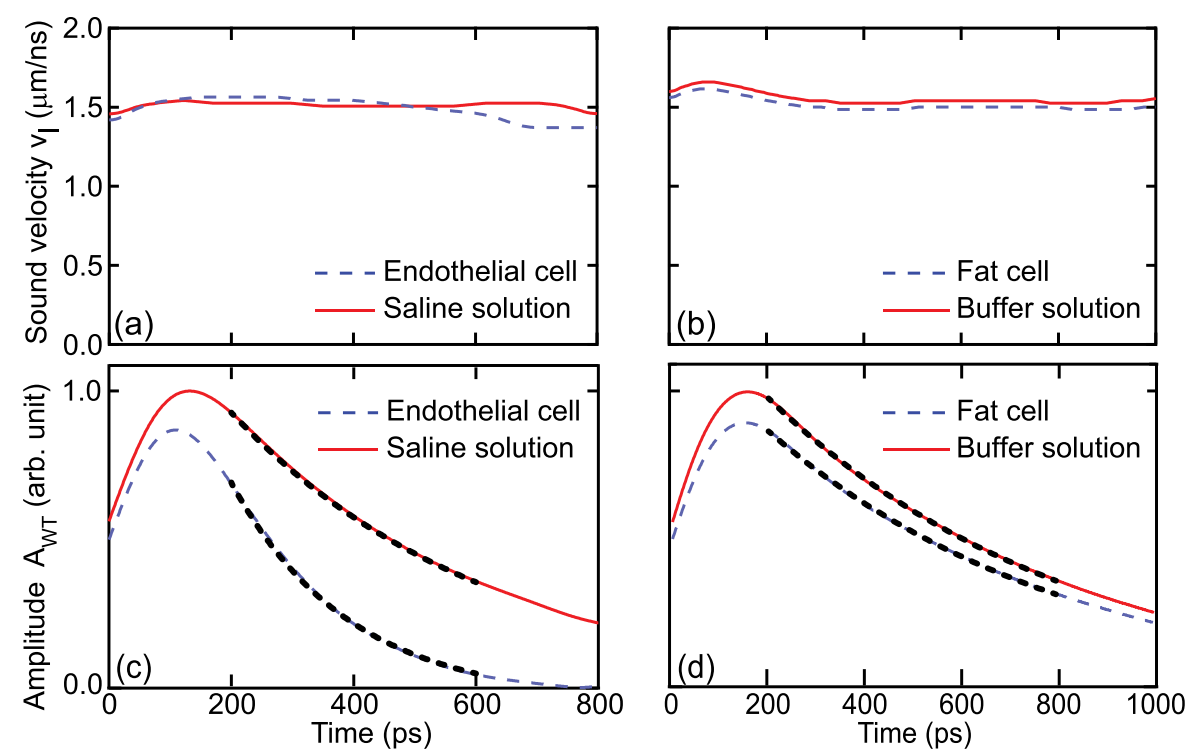

FIG. 5. Calculated sound velocity vs time for (a) endothelial cell and its solution and for (b) fat cell and its solution. (c) and (d) are the corresponding plots for the spatially averaged WT amplitudes at the Brillouin oscillation frequencies. Dotted black lines: fitted exponential decays. for water at $\sim 40{ }^{\circ} \mathrm{C} .{ }^{48}$ Values of $B$ for a bovine aortic endothelial cell and for a fat cell were measured to be 2.63 (Ref. 45) and $2.03 \mathrm{GPa}^{46}$ in agreement with our results to within $2 \%$ and $3 \%$. As expected, $B$ derived for the surrounding solutions are very close to that of water $(B=2.2 \mathrm{GPa}){ }^{49}$

To access ultrasonic attenuation, we plot $A_{W T}$ vs time at $f_{B}$ for each medium in Figs. 5(c) and 5(d). We fit to exponential decays ${ }^{43}$ (dotted black curves), yielding average inverse attenuation times $\tau^{-1}=0.0054$ and $0.0017 \mathrm{ps}^{-1}$ for the endothelial and fat cells. The surrounding saline and buffer solutions yield $\tau^{-1}=0.0024$ and $0.0016 \mathrm{ps}^{-1}$. (The error in $\tau^{-1} \sim 10^{-5} \mathrm{ps}^{-1}$.) The good fits are the result of $\tau^{-1}$ being essentially constant (verified by extracting $d A_{W T} / d t$ as a function of $t$, and noting that the value was approximately constant). The average spatial ultrasonic attenuation coefficients $\alpha=\left(v_{l} \tau\right)^{-1}$, calculated using averaged values of $v_{l}$, are $3.47 \pm 0.04 \mu \mathrm{m}^{-1}$ for the endothelial cell and $1.56 \pm 0.04 \mu \mathrm{m}^{-1}$ for its surrounding solution, whereas for the fat cell the corresponding values are $1.10 \pm 0.01$ and $1.05 \pm 0.01 \mu \mathrm{m}^{-1}$. These values are typical for cells and solutions in the $\mathrm{GHz}$ range. ${ }^{20,22}$ Lipid droplets in fat cells are filled with neutral lipids, and do not contain proteins and DNA. In contrast, the cytoplasm of endothelial cells is filled with proteins and organelles. This accounts for the differences in average physical properties between fat cells and endothelial cells.

In conclusion, using picosecond ultrasonics, we have demonstrated $3 \mathrm{D}$ in vitro biological-cell imaging and shown how continuous-wavelet transforms can be used to process the data sets obtained. This technique allows one to derive important physical values of cell samples, namely, sound velocities, bulk moduli, and ultrasonic attenuation coefficients. The averaged values for these properties derived from experiment show good agreement with those previously documented. In future, by the use of longer data acquisition times or use of acoustic contrast agents it should be possible to extend this technique to locally study the features inside cells through images of $A_{W T}(x, y), v_{l}(x, y)$, and $\alpha(x, y)$ at different times. In addition, lowering the laser power or using substrates of higher thermal conductivity would open the way to in vivo imaging. Such studies should be invaluable for investigating the mechanical properties of cell organelles in both vegetal and animal cells.

${ }^{1}$ G. Bao and S. Suresh, Nat. Mater. 2, 715 (2003).

${ }^{2}$ J. C. Neto, U. Agero, R. T. Gazzinelli, and O. N. Mesquita, Biophys. J. 91, 1108 (2006)

${ }^{3}$ A. S. Tunis, G. J. Czarnota, A. Giles, M. D. Sherar, J. W. Hunt, and M. C. Kolios, Ultrasound Med. Biol. 31, 1041 (2005).

${ }^{4}$ K. J. Van Vliet, G. Bao, and S. Suresh, Acta Mater. 51, 5881 (2003).

${ }^{5}$ N. Wang, E. Ostuni, G. M. Whitesides, and D. E. Ingber, Cell Motil. Cytoskeleton 52, 97 (2002).

${ }^{6} \mathrm{~N}$. Wang, J. Butler, and D. Ingber, Science 260, 1124 (1993).

${ }^{7}$ L. E. Dike, C. S. Chen, M. Mrksich, J. Tien, G. M. Whitesides, and D. E. Ingber, In Vitro Cell. Dev. Biol. Anim. 35, 441 (1999).

${ }^{8}$ J. Y. Shao and R. M. Hochmuth, Biophys. J. 71, 2892-2901 (1996).

${ }^{9}$ A. Ashkin and J. Dziedzic, Science 235, 1517 (1987).

${ }^{10}$ J. Guck, R. Ananthakrishnan, H. Mahmood, T. J. Moon, C. C. Cunningham, and J. Käs, Biophys. J. 81, 767 (2001).

${ }^{11}$ S. Smith, L. Finzi, and C. Bustamante, Science 258, 1122 (1992).

${ }^{12}$ A. Ishijima, T. Doi, K. Sakurada, and T. Yanagida, Nature 352, 301 (1991).

${ }^{13}$ J. Seog, D. Dean, A. Plaas, S. Wong-Palms, A. J. Grodzinsky, and C. Ortiz, Macromolecules 35, 5601 (2002).

${ }^{14}$ R. Merkel, P. Nassoy, A. Leung, K. Ritchie, and E. Evans, Nature 397, 50 (1999).

${ }^{15} \mathrm{E}$. Strohm and M. Kolios, in Engineering in Medicine and Biology Society, EMBC 2009, Annual International Conference of the IEEE (2009), pp. 6042-6045.

${ }^{16}$ E. C. Weiss, P. Anastasiadis, G. Pilarczyk, R. M. Lemor, and P. V. Zinin, IEEE Trans. Ultrason., Ferroelectr., Freq. Control 54, 2257 (2007).

${ }^{17}$ S. Brand, E. C. Weiss, R. M. Lemor, and M. C. Kolios, Ultrasound Med. Biol. 34(9), 1396-1407 (2008).

${ }^{18}$ C. Thomsen, J. Strait, Z. Vardeny, H. Maris, J. Tauc, and J. Hauser, Phys. Rev. Lett. 53, 989 (1984).

${ }^{19}$ C. Thomsen, H. T. Grahn, H. J. Maris, and J. Tauc, Phys. Rev. B 34, 4129 (1986).

${ }^{20}$ C. Rossignol, N. Chigarev, M. Ducousso, B. Audoin, G. Forget, F. Guillemot, and M. C. Durrieu, Appl. Phys. Lett. 93, 123901 (2008).

${ }^{21}$ M. Ducousso, C. Rossignol, B. Audoin, F. Guillemot, and M. C. Durrieu, in 2008 IEEE Ultrasonics Symposium (IUS) (IEEE, 2008), pp. 574-577.

${ }^{22}$ B. Audoin, C. Rossignol, N. Chigarev, M. Ducousso, G. Forget, F. Guillemot, and M. C. Durrieu, Ultrasonics 50, 202 (2010).

${ }^{23}$ T. Dehoux and B. Audoin, J. Appl. Phys. 112, 124702 (2012).

${ }^{24}$ M. Abi Ghanem, T. Dehoux, O. F. Zouani, A. Gadalla, M.-C. Durrieu, and B. Audoin, J. Biophotonics 7, 453 (2014).

${ }^{25}$ T. Dehoux, M. A. Ghanem, O. F. Zouani, M. Ducousso, N. Chigarev, C. Rossignol, N. Tsapis, M.-C. Durrieu, and B. Audoin, Ultrasonics 56, 160 (2015).

${ }^{26}$ A. Gadalla, T. Dehoux, and B. Audoin, Planta 239, 1129 (2014). 
${ }^{27}$ O. F. Zouani, T. Dehoux, M.-C. Durrieu, and B. Audoin, Soft Matter 10, 8737 (2014).

${ }^{28}$ T. Ohashi, Y. Sugaya, N. Sakamoto, and M. Sato, J. Biomech. 40, 2399 (2007).

${ }^{29}$ N. Sakamoto, N. Saito, X. Han, T. Ohashi, and M. Sato, Biochem. Biophys. Res. Commun. 395, 264 (2010).

${ }^{30}$ See supplementary material at http://dx.doi.org/10.1063/1.4918275 for movies of $\delta R$ and $A_{W T}$ for the endothelial and fat cells and the calculation for the temperature distribution.

${ }^{31}$ S. T. Hess, T. P. K. Girirajan, and M. D. Mason, Biophys. J. 91, 4258-4272 (2006).

${ }^{32}$ M. J. Rust, M. Bates, and X. Zhuang, Nat. Methods 3, 793-795 (2006).

${ }^{33}$ T. Ohashi, K. Hanamura, D. Azuma, N. Sakamoto, and M. Sato, J. Biomech. Sci. Eng. 3, 63 (2008).

${ }^{34}$ M. Nagayama, T. Uchida, and K. Gohara, J. Lipid Res. 48, 9 (2007).

${ }^{35}$ H. N. Lin, R. J. Stoner, H. J. Maris, J. Harper, C. Cabral, J. M. Halbout, and G. W. Rubloff, Appl. Phys Lett. 61, 2700 (1992).

${ }^{36}$ L. J. Shelton, F. Yang, W. K. Ford, and H. J. Maris, Phys. Status Solidi B 242, 1379 (2005).

${ }^{37}$ M. Hase, M. Kitajima, A. M. Constantinescu, and H. Petek, Nature 426, 51 (2003).
${ }^{38}$ The slight horizontal banding is thought to be an artifact of the signal acquisition and interpolation.

${ }^{39}$ G. A. Truskey, J. S. Burmeister, E. Grapa, and W. M. Reichert, J. Cell Sci. 103, 491 (1992).

${ }^{40}$ F. Lanni, A. S. Waggoner, and D. L. Taylor, J. Cell Biol. 100, 1091 (1985).

${ }^{41}$ R. M. Pearson, Cont. Lens Anterior Eye 36, 136 (2013).

${ }^{42}$ L. Diéguez, N. Darwish, M. Mir, E. Martínez, M. Moreno, and J. Samitier, Sens. Lett. 7, 851 (2009).

${ }^{43}$ The range of validity of the WT data was verified by synthetic sinusoidal signals: $200-600 \mathrm{ps}$ and $200-800 \mathrm{ps}$ for the endothelial and fat cells, respectively.

${ }^{44}$ A. Najmi and J. Sadowsky, J. Hopkins APL Tech. D 18, 134 (1997).

${ }^{45}$ M. Boynard, M. P. Wautier, P. Perrotin, and J. L. Wautier, Eur. J. Ultrasound 12, 81 (2000).

${ }^{46}$ G. D. Fullerton and J. A. Zagzebski, Medical Physics of $C T$ and Ultrasound: Tissue Imaging and Characterization, Medical Physics Monograph (The American Institute of Physics, 1980).

${ }^{47}$ D. Lemonnier, J. Clin. Invest. 51, 2907 (1972).

${ }^{48}$ G. Kell, J. Chem. Eng. Data 20, 97 (1975).

${ }^{49}$ T. K. Kari and J. V. Matti, Handbook of Hydraulic Fluid Technology (Marcel Dekker, Inc., 1999). 